\title{
Recuperação de plantas de genótipos de aceroleira afetadas por geada no norte do Paraná
}

\author{
Plant survival of barbados cherry genotypes after \\ frost injury in northern Parana State
}

\author{
Carmen Silvia Vieira Janeiro Neves ${ }^{1 *}$; Ives Massanori Murata ${ }^{2}$; \\ Fernando Tsuyoshi Aida ${ }^{3}$; Andrey Vetorelli Borges ${ }^{3}$; Inês Cristina de Batista Fonseca ${ }^{1}$
}

\begin{abstract}
Resumo
A aceroleira é uma planta de clima tropical que também tem sido cultivada em áreas subtropicais, ficando com isso sujeita à ocorrência de geadas, que causam danos consideráveis à folhagem e podem levar as plantas à morte. As geadas de julho de 2000 no Norte do Paraná possibilitaram a avaliação de 19 genótipos de acerola, propagados vegetativamente. A temperatura mínima foi de $-1,3^{\circ} \mathrm{C}$ no abrigo meteorológico em 17 de julho, que corresponde a $-5,4{ }^{\circ} \mathrm{C}$ na relva. Todas as plantas tiveram danos em $100 \%$ das folhas. No ano seguinte à geada, avaliou-se a recuperação das plantas com base na brotação apresentada. Com os resultados obtidos, conclui-se que os genótipos de aceroleira apresentam respostas diferentes à geada, sendo que alguns são levados à morte e outros conseguem se recuperar na estação de crescimento seguinte. Os genótipos que apresentaram melhor recuperação foram: 'Cícero', 'Roseli', 'Carolina' e 'Lígia'. Os resultados são discutidos em relação às temperaturas-limite relatadas na literatura.
\end{abstract}

Palavras-chave: Malpighia emarginata, variedades, frio, dano.

\begin{abstract}
Barbados cherry is a tropical fruit that when cultivated in subtropical areas is exposed to frosts which cause considerable damages to the leaves and can kill plants. The frosts of July 2000 in Northern Paraná State made possible the evaluation of 19 Barbados cherry genotypes propagated through cuttings. A minimum air temperature of $-1,3^{\circ} \mathrm{C}$ was recorded on 17 July at the meteorological station; the minimum ground temperature was around $-5,4^{\circ} \mathrm{C}$. All plants were severely injured in $100 \%$ of leaves. The evaluation was made the following year to the frost, through sprouts status. It was observed that Barbados cherry genotypes present differences in cold hardiness. Some genotypes were killed and others survived, with good vegetation on the next year. The following genotypes presented the best recovery: 'Cícero', 'Roseli', 'Carolina' and 'Lígia.' The findings are discussed in relation to temperature limits reported in the literature.
\end{abstract}

Key words: Malpighia emarginata, varieties, cold, damage

1 Eng. Agr., Dr., Professora do Depto. de Agronomia, Universidade Estadual de Londrina, Londrina. Email: csvjneve@uel.br

2 Eng. Agr., Ms., Doutorando em Agronomia, Universidade Estadual de Londrina, Londrina. Bolsista CAPES.

3 Acadêmico de Agronomia, Universidade Estadual de Londrina, Londrina.

* Autor para correspondência. 
A acerola (Malpighia emarginata D.C.) ou Cereja das Antilhas é uma fruta originária da América Central e Norte da América do Sul. Foi introduzida no Brasil na década de 40, mas só adquiriu expressão como cultura comercial a partir da década de 90 , impulsionada por seu alto teor de ácido ascórbico, sendo consumida "in natura" e utilizada na indústria de alimentos e de suplementos vitamínicos (ARAÚJO; MINAMI, 1994).

A acerola é produzida no Estado do Paraná principalmente nas regiões Norte e Noroeste (STENZEL; MOTTER, 1995). Embora apresentem condições climáticas normalmente adequadas para o cultivo desta espécie, essas regiões se encontram sujeitas à ocorrência de geadas entre maio e agosto. De acordo com Simão (1998) e Marino Netto (1986), a aceroleira é rústica e desenvolve-se bem em clima tropical e subtropical, possui folhas persistentes que resistem a temperaturas próximas a $0{ }^{\circ} \mathrm{C}$. Para seu cultivo, é recomendada a temperatura média anual acima de $20{ }^{\circ} \mathrm{C}$ ou a temperatura do mês mais frio acima de $14{ }^{\circ} \mathrm{C}$ (TEIXEIRA; AZEVEDO, 1995). Aceroleiras resistiram, sem danos, a temperaturas de $2{ }^{\circ} \mathrm{C}$ e a geadas leves na região de Limeira - SP (ARAÚJO; MINAMI, 1994).

O objetivo do presente trabalho foi avaliar a recuperação de plantas de 19 genótipos de aceroleira após as geadas ocorridas no inverno de 2000 no Estado do Paraná.

O pomar estudado localiza-se na Fazenda Escola da Universidade Estadual de Londrina, em Londrina, PR, em Latossolo Vermelho distroférrico. O clima da região, segundo a classificação de Köppen, é do tipo Cfa, subtropical úmido, com chuvas em todas as estações, podendo ocorrer seca no período de inverno. A temperatura média anual é de $20,7^{\circ} \mathrm{C}$, a temperatura dos meses mais frios é de $16,6^{\circ} \mathrm{C}$ (junho) e $16,8^{\circ} \mathrm{C}$ (julho), e a insolação média diária é de 7,01 horas. A altitude é de 566 metros e as coordenadas são $23^{\circ} 23^{\prime} \mathrm{S}$ e $51^{\circ} 11^{\prime} \mathrm{W}$ (CORRÊA; GODOY; BERNARDES, 1982). Os dados meteorológicos diários foram obtidos na Estação
Meteorológica do Instituto Agronômico do Paraná IAPAR, Londrina, PR.

As plantas de aceroleira, de um trabalho de seleção de genótipos (CARPENTIERI-PÍPOLO et al., 2000), foram formadas por meio de estaquia e na ocasião da avaliação estavam com 5 anos de idade. Entre 13 e 25 de julho de 2000 foram constatados sete episódios de geadas, sendo mais rigorosa a de 17 de julho, com temperatura de $-1,3{ }^{\circ} \mathrm{C}$ no abrigo meteorológico, conforme se observa na Figura 1. Todas as plantas da coleção tiveram suas folhas totalmente danificadas pelas geadas. Para estimular a recuperação das plantas, no final do inverno elas foram podadas drasticamente, deixando-se apenas os troncos, com $10 \mathrm{~cm}$ de altura. Na primavera e no verão seguintes a maioria das plantas apresentou brotações. Esta brotação foi avaliada visualmente em relação ao desenvolvimento da nova copa em duas ocasiões, a primeira em abril de 2001 e a segunda em setembro de 2001, para confirmação dos resultados. Para isso, elaborou-se a seguinte escala de notas, com base no desenvolvimento das plantas:

1- Planta morta (sem brotações).

2- Planta pouco recuperada (poucas brotações).

3- Planta medianamente recuperada (número médio de brotações).

4- Planta totalmente recuperada (grande número de brotações).

Foram avaliadas nove plantas de cada um dos 19 genótipos, totalizando 171 plantas. Os dados obtidos foram analisados num delineamento inteiramente casualizado com o teste não paramétrico de Kruskal-Wallis, que é usado para verificar se $\mathrm{K}$ $(K>2)$ amostras independentes diferem entre si e é válido para variáveis em escala ordinal (escala de notas). O procedimento usado consiste basicamente, em substituir o valor da variável original pelo posto obtido na distribuição conjunta dos escores das $\mathrm{K}$ amostras. A utilização deste teste segue as etapas: 1) ordenar os dados dos $\mathrm{K}$ grupos (amostras) em uma única série e atribuir postos de 1 a $n$ 
para os $n$ escores; 2) calcular a soma dos postos e os postos médios de cada amostra; 3) calcular a estatística H com Distribuição Qui-Quadrado com $\mathrm{K}-1$ graus de liberdade; 4) no caso de resultar $\mathrm{H}$ significativo, efetuar os contrastes entre pares de postos médios dos grupos (GOMES, 2000).

As geadas causaram $100 \%$ de danos às folhas de todos os genétipos. As plantas do presente trabalho foram expostas a sete geadas, com temperaturas mínimas no abrigo meteorológico de $-1,3$ até $4,2^{\circ} \mathrm{C}$ ( $\mathrm{Fi}$ gura1). De acordo com Sentelhas, Ortolani e Pezzapone (1995), comparando dados históricos de dez localidades do Estado de São Paulo, em noites de geada a temperatura mínima do ar registrada na relva, é, em média, $4,1^{\circ} \mathrm{C}$ menor do que a temperatura no abrigo. Portanto, a temperatura no pomar em julho de 2000 foi de $-5,4$ até $0,1^{\circ} \mathrm{C}$. Isto confirma o observado por Sentelhas et al. (1996), que classificaram a aceroleira como moderadamente tolerante ao frio, pois, em condições controladas, as plantas tiveram $100 \%$ de danos nas folhas quando a temperatura foi $-4^{\circ} \mathrm{C}$, o que corresponde a $0^{\circ} \mathrm{C}$ no abrigo. Entretanto, esses autores não fazem referência a cultivares de aceroleira, uma vez que as plantas utilizadas naquele estudo eram propagadas por sementes, o que leva a variabilidade devido à segregação genética.

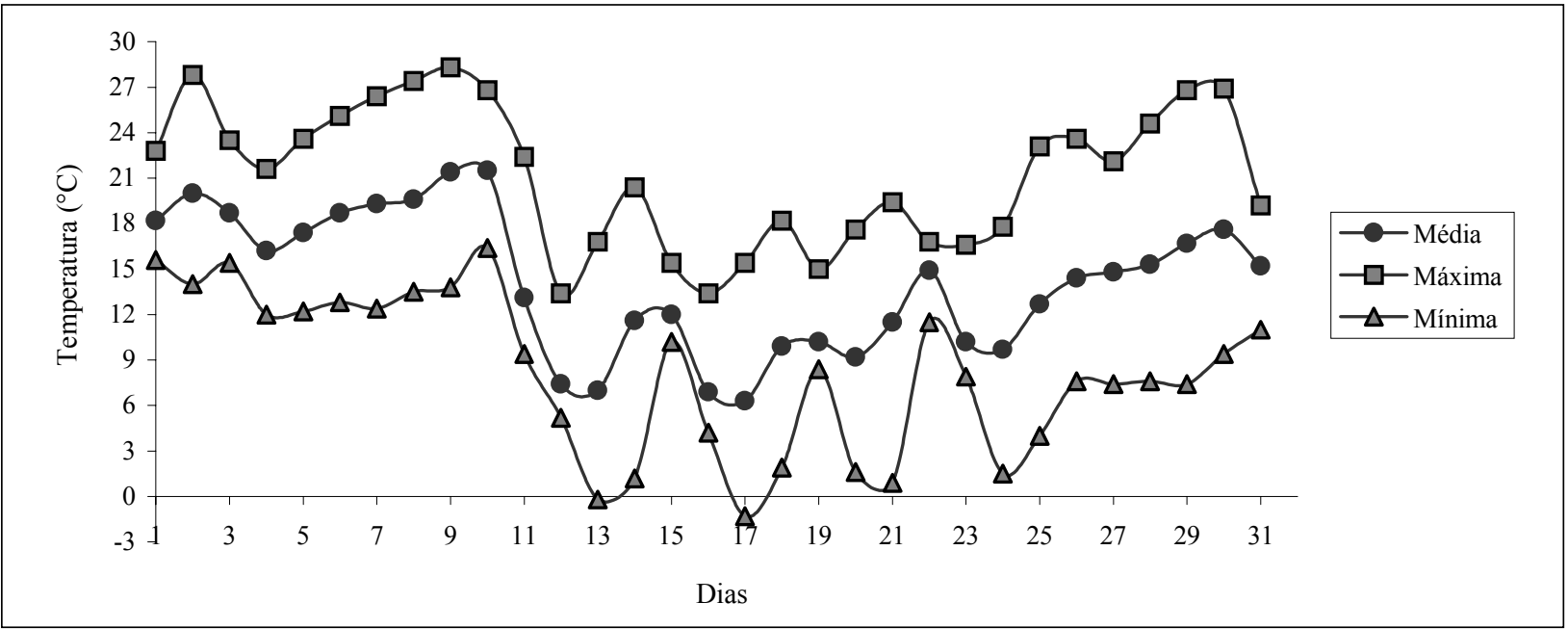

Figura 1 - Temperaturas média, máxima e mínima do ar registradas na Estação Meteorológica do IAPAR, em Londrina, em julho de 2000.

Na Tabela 1 pode-se observar as médias das notas resultantes da avaliação visual realizada nos genótipos de aceroleira em relação à recuperação das plantas em setembro de 2001. Observa-se que os genótipos apresentaram diferenças significativas, sendo 'Cícero' considerado o que mais se recuperou, seguido de 'Roseli', 'Carolina' e 'Lígia'.
Os seguintes genótipos tiveram média recuperação: 'Carla', 'Dominga', Valéria', 'Eclipse', 'Neusa', 'Valter', 'Manuel' e 'Samurai'. O genótipo ‘Glória' foi o que apresentou a pior recuperação, seguido de 'Vítor', 'Paulo', 'Natália', 'Paulinho', 'Cristina' e 'Luiza'. 
Tabela 1 - Notas médias atribuídas aos genótipos de acerola e respectivos postos médios em relação à recuperação das plantas após as geadas de julho de 2000 em Londrina (média de 9 repetições).

\begin{tabular}{llc}
\hline Genótipo & Nota $^{1}$ & Posto Médio $^{2}$ \\
\hline Dominga & 2,66 & $100,5 \mathrm{abcd}$ \\
Roseli & 3,22 & $122,1 \mathrm{ab}$ \\
Eclipse & 2,44 & $91,4 \mathrm{abcde}$ \\
Samurai & 2,11 & $81,4 \mathrm{abcdef}$ \\
Glória & 1,22 & $41,6 \quad \mathrm{f}$ \\
Neusa & 2,44 & $91,4 \mathrm{abcde}$ \\
Cícero & 3,33 & $126,9 \mathrm{a}$ \\
Carla & 2,67 & $100,9 \mathrm{abc}$ \\
Valéria & 2,66 & $100,5 \mathrm{abcd}$ \\
Valter & 2,56 & $96,8 \mathrm{abcde}$ \\
Carolina & 2,89 & $107,7 \mathrm{ab}$ \\
Lígia & 2,89 & $107,7 \mathrm{ab}$ \\
Luiza & 2,11 & $79,8 \mathrm{bcdef}$ \\
Cristina & 2,11 & $77,5 \mathrm{bcdef}$ \\
Manuel & 2,33 & $90,9 \mathrm{abcde}$ \\
Vítor & 1,44 & $52,2 \quad$ ef \\
Natália & 1,57 & $54,8 \quad$ def \\
Paulinho & 1,56 & $57,6 \quad$ cdef \\
Paulo & 1,44 & $52,2 \quad$ ef \\
\hline
\end{tabular}

${ }^{1}$ Nota $1=$ planta morta (sem brotações); nota $2=$ planta pouco recuperada (poucas brotações); nota $3=$ planta medianamente recuperada (número médio de brotações); nota $4=$ planta totalmente recuperada (grande número de brotações)

${ }^{2}$ Postos seguidos de letras iguais não diferem significativamente pelo teste de Kruskal-Wallis.

Em citros, também foram registradas diferenças na resistência ao frio entre as variedades (TURREL, 1973). Estas diferenças são importantes e devem ser levadas em consideração no planejamento de pomares, principalmente se estes forem instalados em áreas sujeitas à ocorrência de geadas. De acordo com Teixeira e Azevedo (1995), que analisaram dados climáticos de áreas produtoras de acerola do Brasil, da América Central e da Flórida, a temperatura média anual ideal para o cultivo dessa fruta é acima de $20^{\circ} \mathrm{C}$ ou a temperatura do mês mais frio acima de 14 ${ }^{\circ} \mathrm{C}$. Entretanto, é importante que além desses dados, seja observada a freqüência da ocorrência de geadas pois a média histórica de Londrina para o mês de julho é de $16,8^{\circ} \mathrm{C}$ e a média do mês de julho de 2000 foi de $14,1^{\circ} \mathrm{C}$, quando ocorreram as geadas relatadas no presente trabalho.

Com os resultados obtidos no presente trabalho conclui-se que os genótipos de aceroleira apresentam respostas diferentes à geada, sendo que alguns podem mesmo ser levados à morte, enquanto que outros conseguem se recuperar na estação de crescimento seguinte.

\section{Agradecimentos}

Os autores agradecem ao Instituto Agronômico do Paraná - IAPAR, pelo fornecimento dos dados meteorológicos.

\section{Referências}

ARAÚJO, P. S. R.; MINAMI, K. Acerola. Campinas: Fundação Cargill, 1994.

CARPENTIERI-PÍPOLO, V. et al. Acerola UEL 3-Dominga, Acerola UEL 4 -Lígia e Acerola UEL 5 - Natália. In: DONADIO, L. C. Novas variedades brasileiras de frutas. Jaboticabal: Sociedade Brasileira de Fruticultura, 2000. p.28-33.

CORRÊA, A. R.; GODOY, H.; BERNARDES, A. R. M. Características climáticas de Londrina. 2.ed. Londrina: IAPAR, 1982.

GOMES, F.P. Curso de estatística experimental. 14.ed. Piracicaba: F. Pimentel Gomes, 2000.

MARINO NETTO, L. Acerola: a cereja tropical. São Paulo: Nobel, 1986.

STENZEL, N. M. C.; MOTTER, A. A. Cultura de acerola no estado do Paraná: pesquisa e extensão. In: SÃO JOSÉ, A. R.; ALVES, R. E. Acerola no Brasil: produção e mercado. Vitória da Conquista: UESB. 1995. p.130-132.

SENTELHAS, P. C. et al. Temperatura letal de diferentes plantas frutíferas tropicais. Bragantia, Campinas, v.55, n.2, p.231-235, 1996. 
SENTELHAS, P. C.; ORTOLANI, A. A.; PEZZAPONE, J. R. M. Estimativa de temperatura mínima de relva e da diferença de temperatura entre o abrigo e a relva em noites de geada. Bragantia, Campinas, v.54, n.2, p.437-445, 1995.

SIMÃO, S. Tratado de fruticultura. Piracicaba: FEALQ, 1998.
TEIXEIRA, A. H. C.; AZEVEDO, P.V. Índices-limite do clima para o cultivo da acerola. Pesquisa Agropecuária Brasileira, Brasília, v.30, n.12, p.1403-1410, 1995.

TURRELL, F. M. The science and technology of frost protection. In: REUTHER, W. The citrus industry. Riverside: University of California, 1973. p.338-446. 
